\title{
Sleep patterns and sleep-related complaints of Brazilian interstate bus drivers
}

M.T. Mello

M.G. Santana2, L.M. Souza², P.C.S. Oliveira², M.L. Ventura ${ }^{3}$,

C. Stampi $i^{4}$ and S. Tufik ${ }^{5}$

\author{
1Departamento de Educação Física e Esportes, \\ Núcleo Inter-disciplinar de Fisiologia do Exercício e Psicobiologia, \\ Universidade Federal de Uberlândia, U berlândia, M G, Brasil \\ 'U niversidade Federal de Goiás, Campus Avançado de Catalão, Catalão, \\ GO, Brasil \\ ${ }^{3}$ Asso ciação Fundo de Incentivo à Psicofarmacologia, São Paulo, SP, Brasil \\ ${ }^{4}$ Chronobiology Research Institute, Newton, MA, USA \\ ${ }^{5}$ Departamento de Psicobiologia, Universidade Federal de São Paulo, \\ São Paulo, SP, Brasil
}

\section{Correspondence}

M.T. Mello

Departamento de Psicobiologia UNIFESP/EPM

Rua Botucatu, 862, $1^{\circ}$ andar

04062-023 São Paulo, SP

Brasil

E-mail: tmello@psicobio.epm.br or

tmello@ufu.br

Research supported by Associação

Fundo de Incentivo à

Psicofarmacologia (AFIP),

Confederação Nacional de

Transportes (CNT) and Nacional

Expresso (Brazilian bus company).

Publication supported by FAPESP.

Received July 7, 1998

Accepted November 8, 1999

\section{Abstract}

Sleep-related complaints have become a highlight for physicians as well as public health administrators. Studies of sleep patterns and sleep-related complaints of shift workers have been useful in minimizing reduction in the quality of life due to the warping of the sleep-wake cycle. The objective of the present study was to assess patterns of sleep, sleep-related complaints as well as physical activity and scoring rates for depression and anxiety in interstate bus drivers. Data were obtained with a sleep questionnaire, with the Beck inventory for depression, and the State-Trait Anxiety Inventory (STAI). A total of 400 interstate bus drivers from the northern, southern, central-western and south-eastern regions of Brazil were interviewed. Sixty percent of the subjects interviewed presented at least one sleep-related complaint, $16 \%$ admitted to have dozed at the wheel while on duty, and $41 \%$ stated that they exercised on a regular basis. Other sleep disturbance complaints reported were: sleep latency 29'17"; physical fatigue, $59.8 \%$; mental fatigue, $45.4 \%$; sleepiness, $25.8 \%$; irritability, $20.6 \%$; insomnia, $37.5 \%$, respiratory disturbances, $19.25 \%$ and snoring, $20.75 \%$. Scores for anxiety and depression were not in the pathological range. The present data reinforce the view that bus drivers are generally discontent with shift work and its effects on sleep. Consequently, it is very important to establish an appropriate work schedule for drivers, besides implementing photo-therapy and physical activities in order to minimize sleepiness when driving.

\section{Introduction}

Sleep-related complaints have become a highlight for physicians as well as public health administrators, with increasing interest in recent decades. It has become apparent
Key words

- Sleep

- Sleep-related disorders

- Shift workers

- Depression

- Anxiety

- Physical activity that the majority of people with sleep-related complaints suffer from excessive daytime sleepiness, insomnia, irritability and stress. Studies on sleep patterns and sleep-related complaints in shift workers have been useful in minimizing the reduction in the quality of 
life due to the warping of the sleep-wake cycle (1). According to the Florez-Lozano study (2), long working hours may cause irritability, physical and mental fatigue, excessive sleepiness, insomnia, and gastric ulcers and may also result in loss of attention and an increased number of accidents in the work place. Excess caffeine intake, tobacco and drug consumption and even eating food of low nutritional value could all have negative effects on sleep hygiene. Some studies have suggested simple alternatives in an attempt to minimize sleep-related complaints in shift workers. Stampi et al. (3) outlined the positive aspects of a broken sleep regimen which minimized sleep-related complaints.

The objective of the present study was to evaluate the sleep patterns and sleep-related complaints as well as the anxiety and depression scores of interstate bus drivers.

\section{Material and Methods}

The data were obtained through a validated sleep questionnaire designed by the Department of Psychobiology of Escola Paulista de Medicina (4) which was used in epidemiological sleep pattern studies in São Paulo in 1987 and 1995. For the current study, additional questions were included referring to driving styles, eating habits and fitness. The Beck inventory was used to measure the degree of depression (5) and the State-Trait Anxiety Inventory (STAI) (6) was also applied.

The sleep questionnaire (4) consists of 96 easy to understand questions for the identification of sleep patterns and possible sleeprelated complaints, as well as physical activity, social class and educational level of the interviewees. The results obtained in response to the items in the sleep questionnaire were crossed with each other to obtain the index of sleep satisfaction and efficiency and also to correlate the complaints with the major habits or the routine of the individual.
The Beck inventory (5) consists of a scale with 21 selected items concerning the most common symptoms associated with depression. Each item is listed with 4 degrees in increasing or decreasing order of severity, and the score for each item is $0-3$. The categories in the scale include mood, pessimism, guilt, social isolation, sleeping and eating disorders, loss of libido, lack of interest in work, and the wish to cry. In general, the content emphasizes pessimism, the feeling of having failed and the wish for selfpunishment. The Beck inventory represents a cognitive approach to depression and its causes.

The STAI (6) consists of two different scales elaborated to measure two concepts of anxiety: anxiety state (A-state) and anxiety trait (A-trait). This measure demonstrates the predisposition, concerning a personality trait, in realizing a major or minor anxiogenic situation, depending on the acquired score. The anxiety trait scale consists of twenty statements with 1 to 4 points in which the person examined describes how he generally feels. The anxiety trait represents a latent disposition, a personality characteristic, or the general tendency of a person to perceive various situations as threatening. The overall scores for this scale (trait) range from 20 to 80. In the present study we used only the STAI in order to determine the degree of anxiety. Nevertheless, a high degree of anxiety and scores that are equal to 50 or greater are considered. This anxiety scale is determined as the following: 31 to 49 are scores that represent the average that is expected for the sample; scores below 30 indicate a low degree of anxiety; scores above 50 indicate a high degree of anxiety; however, this does not mean a pathologic situation.

A total of 400 male bus drivers responded to the sleep questionnaire. Data pertaining to weekly work schedules, schooling, marital status and responses to questions specifically related to sleep, drug and alcohol intake, 
use of hypnotic drugs and stimulants, physical exercise, degree of anxiety and depression were collated. The questionnaires were completed at the bus drivers' depots and/or at bus stations or stops when drivers were off duty. Respondents came from the northern, southern, central-western and south-eastern regions of Brazil.

Data about the number of drivers that practice physical activities, considering the main complaints about sleep disturbances, were raised. The data were then compared to the ones that were raised together with the sedentary drivers. These data were crosschecked with the sleep disturbance data in order to evaluate the physical activity influence on the sleep patterns, since some studies have shown this influence (7).

Data were analyzed statistically by descriptive analysis, taking into consideration the average and the percentage of each variable (8).

\section{Results}

The 400 respondents interviewed were assigned to the following groups: $27(6.5 \%)$ permanent day shift, 42 (10.5\%) permanent night shift, $30(7.5 \%)$ on shift work based on a permanent scale, and 301 (75.3\%) on shift work based on a flexi scale. With respect to the weekly schedule, $5(1.3 \%)$ drivers worked up to $20 \mathrm{~h}, 123$ (30.8\%) between 21 and $40 \mathrm{~h}$, $210(52.5 \%)$ between 41 and $50 \mathrm{~h}, 50(12.5 \%)$ between 51 and $60 \mathrm{~h}$, and $12(3.0 \%)$ more than $60 \mathrm{~h}$. Forty-seven $(11.8 \%)$ belonged to social classes A and B, 251 (63.1\%) to class $\mathrm{C}$, and $100(21.1 \%)$ to classes $\mathrm{D}$ and $\mathrm{E}$ (Table 1). The criterion used to socially classify the interviewees was based on the parameters that rule the classification adopted by ABIPEME (9). With respect to educational level, 103 (25.8\%) had completed junior high school, $244(61.0 \%)$ had failed to complete junior high school, $24(6.0 \%)$ had graduated from senior high school, 26(6.5\%) had failed to graduate from senior high school, $1(0.3 \%)$ had completed higher education, and $2(0.6 \%)$ had never attended school (Table 2). With respect to marital status, $326(81.5 \%)$ were married, $1(0.3 \%)$ was a widower, $33(8.3 \%)$ were divorced, 4 $(1.0 \%)$ were separated, $8(2.0 \%)$ had steady partners, and $28(7.0 \%)$ were single (Table $3)$.

Table 4 presents the responses to the questions about sleep-related complaints and patterns, and the use of psychotropic drugs. Table 5 shows data pertaining to the sleep section of the questionnaire, Beck inventory and trait anxiety of the STAI.

With respect to physical activity, 165

Table 1 - Social class of the drivers interviewed based on ABIPEME criteria (9) ( $\mathrm{N}=398)$.

\begin{tabular}{lcc}
\hline Social class & $\begin{array}{c}\text { Number of } \\
\text { respondents }\end{array}$ & \% of respondents \\
\hline A/B & 47 & 11.8 \\
C & 251 & 63.1 \\
D/E & 100 & 21.1
\end{tabular}

Table 2 - Academic background of the participants $(\mathrm{N}=400)$.

\begin{tabular}{lcc}
\hline Academic background & $\begin{array}{c}\text { Number of } \\
\text { respondents }\end{array}$ & $\begin{array}{c}\% \text { of } \\
\text { respondents }\end{array}$ \\
\hline No formal schooling & 2 & 0.6 \\
Incomplete junior high & 244 & 61 \\
Complete junior high & 103 & 25.8 \\
Incomplete high school & 26 & 6.5 \\
Complete high school & 24 & 6 \\
University education & 1 & 0.3
\end{tabular}

Table 3 - Marital status of the drivers interviewed $(\mathrm{N}=400)$.

\begin{tabular}{lcc}
\hline Marital status & Respondents & $\begin{array}{c}\% \text { of } \\
\text { respondents }\end{array}$ \\
\hline Married & 326 & 81.5 \\
Widowed & 1 & 0.3 \\
Divorced & 33 & 8.3 \\
Separated & 4 & 1 \\
Steady partner & 8 & 2 \\
Single & 28 & 7 \\
& &
\end{tabular}


(41.3\%) drivers followed some program of fitness activity while $235(58.8 \%)$ did not exercise. In the former group, 5 (3.6\%) exercised 0.05 to 0.5 times per week, $82(49.7 \%)$ 1.0 to 2.5 times, $43(26.1 \%) 3.0$ to 4.0 times, $20(12.1 \%) 4.5$ to 7.0 times, and $14(8.5 \%)$ provided no answer. Table 6 presents the type of physical activity, and Table 7 presents the sleep-related events for drivers who engaged in some type of physical activity and those who did not.

\section{Discussion}

The results obtained demonstrate that

\begin{tabular}{lc} 
Table 4 - Data concerning sleep complaints, sleep \\
pattern and use of psychotropic drugs (N $=400)$. \\
\hline Complaint/Disorder & Results \\
\hline Sleep latency & $29{ }^{\prime} 17$ \\
Number of arousals - daily complaints & 2.01 \\
Physical fatigue & $59.8 \%$ \\
Mental fatigue & $45.4 \%$ \\
Sleepiness & $25.8 \%$ \\
Irritability & $20.6 \%$ \\
Dozed off at the wheel & $16 \%$ \\
Colleagues who have dozed off while & $58 \%$ \\
$\quad$ on duty & \\
Insomnia & $37.5 \%$ \\
Excessive sleepiness & $9.25 \%$ \\
Respiratory disturbances & $19.25 \%$ \\
Snoring & $20.75 \%$ \\
On stimulants & $15.8 \%$ \\
On sleep medication & $7.5 \%$ \\
Consuming alcohol & $48.5 \%$ \\
Smoking & $43.3 \%$ \\
Taking naps & $65.8 \%$ \\
Where naps occur & \\
At home & $83.3 \%$ \\
At the depot & $46.4 \%$ \\
On the bus & $9.9 \%$ \\
No reply & $0.4 \%$ \\
&
\end{tabular}

Table 5 - Mean results obtained through the Beck inventory and State-Trait Anxiety Inventory (STAI) $(\mathrm{N}=400)$

\begin{tabular}{lrr}
\hline & N & Mean \pm SD \\
\hline Beck inventory & 337 & $4.91 \pm 4.91$ \\
STAl & 339 & $32.33 \pm 7.30$
\end{tabular}

some aspects related to the sample characteristics such as social class (class " $\mathrm{C}$ ": $63 \%$ ), educational level (incomplete primary school: $61 \%$ ), and marital status (married: $81 \%$ ) probably contributed to the changes in sleep pattern observed in this sample. This may have happened due to the fact that those aspects help in the increase of the individual's stress, associated to the lack of opportunities for professional growth, since the educational level is not good enough to help them get better jobs and wages.

The results obtained in this study show that $60 \%$ of bus drivers reported at least one sleep complaint. The rate for this group is lower than those obtained for the general population of São Paulo city in 1987 and 1995 studies $(4,10)$, i.e., 76 and $82 \%$, respectively. However, for our specific sample, the $60 \%$ rate can be considered high due to the inherent characteristics of this sample and the presumed state of alertness on the part of drivers who are on duty. However, this score $(60 \%$ of the individuals with sleep alterations) might have been even higher if the interviewees had presented higher educational level and a higher social class (Tables 1 and 2) since several studies have demonstrated that shift workers with these characteristics have a greater perception of loss of quality of life and, consequently, report more directed and specific complaints than individuals of lower social class and educational level (11-13).

Table 4 lists the major complaints reported by the drivers, such as physical and mental fatigue, somnolence, irritability, insomnia, snoring, alcohol consumption, smoking, and dozing at the wheel. One example of this irregular pattern associated with a sleep disturbance is the fact that $16 \%$ of drivers candidly admitted having dozed off at the wheel while on duty. Curiously, when drivers were asked to comment about whether they were aware of a similar situation arising among their colleagues, the figure rose to $58 \%$. 
It can be seen that characteristic complaints such as mental fatigue, irritability and somnolence may be the consequence of a change in sleep architecture leading to a reaction characterized by the behavioral effects mentioned above $(1,3,7,14)$. This fragmentation or reduction of REM sleep may be due to different causes; however, based on the complaints of the drivers themselves, the use of medication, respiratory disorders, snoring and consumption of alcoholic beverages may support the hypothesis of REM sleep deprivation, with a reduction in the satisfaction with one's own sleep as a consequence of these factors.

Another relevant aspect is alcohol consumption, which was reported by $48.5 \%$ of the sample. Alcohol is known to modify sleep in a significant manner, producing both objective alterations observed in the polysonographic (PSG) record and subjective alterations evaluated with scales and questionnaires $(15,16)$.

The sedative effect of alcohol contributes to the level of diurnal somnolence and this effect appears in subjects who undergo total or partial sleep deprivation (17). In this respect, the combination of a work schedule that does not provide the hours needed for reparative rest with alcohol consumption may certainly increase the deleterious effects of the drug.

Mitler et al. (14) hypothesized that an extended situation of stress reduced alertness associated with attention, possibly leading to an increased incidence of accidents in the work place, since the fragmentation of the sleep architecture might result in an increase of sleepiness (15-17).

However, we are encouraged to believe that there is a better correlation between the length of a day's work and the time for rest according to the physiological requirements of each driver. Table 5 shows that the mean values for the degrees of anxiety and depression among drivers are within acceptable ranges for this group $(5,6)$.
Evaluation of the trait anxiety of STAI without previously assessing the state of anxiety of STAI could be responsible for the reduction of the degree of anxiety observed. Furthermore, evaluating trait anxiety is a characteristic of personality, which determines to what extent situations are perceived with greater or lesser anxiety intensity.

According to our results, these subjects showed an index of trait anxiety within acceptable means for the general population. Here, the same restrictions applicable above are equally valid.

A review of the literature indicates that people with a high degree of trait anxiety tend to experience anxiogenic situations with a high degree of state anxiety (6). When this assumption was applied to the subjects of the current study, our volunteers tended to show a medium degree of state anxiety. However, when we considered the results of other

\begin{tabular}{lcc}
$\begin{array}{l}\text { Table } 6 \text { - Data about the physical activities of the } \\
\text { drivers ( } \mathrm{N}=400) \text {. }\end{array}$ \\
\hline Physical activity & Total & $\%$ \\
\hline Walking/strolling & 63 & 38.2 \\
Playing soccer & 62 & 37.6 \\
Bicycle riding & 33 & 20.0 \\
Fitness centers & 10 & 6.1 \\
Swimming/treadmill/ & 6 & 3.6 \\
J iu-J itsu/J udo & & \\
J ogging/running & 6 & 3.6 \\
Gardening and similar & 5 & 3.0 \\
Other activities & 5 & 3.0
\end{tabular}

Table 7 - Data concerning the drivers in relation to the presence or absence of physical activity $(\mathrm{N}=400)$.

\begin{tabular}{lcc}
\hline Questions & $\begin{array}{c}\text { Practice physical } \\
\text { activity (\%) }\end{array}$ & $\begin{array}{c}\text { Do not practice physical } \\
\text { activity (\%) }\end{array}$ \\
\hline With a sleep complaint & 35 & 65 \\
Taking naps & 64.8 & 66.4 \\
Already dozes off at the wheel & 15.2 & 16.6 \\
How many times has this occurred & 4.5 & 6.75 \\
Taking stimulants & 15.2 & 16.2 \\
Consuming alcohol & 43.6 & 51.9
\end{tabular}


parameters analyzed such as alcohol intake (48.5\%) and tobacco consumption (43.3\%) (Table 4) it was not possible to find a characteristic of anxiety. However, we maintain that the evaluation of anxiety levels, which remain unassessed, could shed light on this aspect and warrant further analysis.

We believe that the way in which individual subjects face their routine life and their attitudes in the professional, family and affective fields could, arguably, be expressed as a state anxiety, which has remained unassessed. However, we do not believe that anxiety can only be assessed through the trait anxiety of STAI even if the latter provides an average picture, since this may hide a state anxiety, which does not concur with this average. The data in Table 6 suggest that the difference between the notion of physical activity and physical exercise was not clearly understood by the respondents. According to McArdle et al. (18), physical activity is any movement of the body that expends energy, whereas physical exercise is a physical activity that is planned, structured, repetitive and intentional. Physical aptitude is a sum of attributes relative to the capacity of carrying out some type of physical activity, which may be related to health such as cardiorespiratory and muscle endurance, muscle strength, body building and flexibility of the joints. Health is considered to be physical, mental and social well being and not simply an absence of disease.

Physical activity is a generic expression of which exercise represents a main component. Independent of age, regular physical activity promotes normal physiological rates, which depend on the initial condition of fitness, age and the type of physical training undertaken. Open involvement in physical activity early on in life does not seem to play a role in fostering longevity or promoting good health (18).

Analysis of Table 7 shows a lower incidence of sleep-related complaints and alcohol consumption in drivers who exercise.
However, other data did not show any appreciable difference. On this basis, a thorough analysis of the frequency of the type of physical activity and the physiological parameters such as $\mathrm{VO}_{2}$ max, anaerobic threshold, fat percent, ideal and real weight should be undertaken in a laboratory setting and correlated to data obtained by computed PSG for a better understanding of this topic.

The warping of the sleep-wake cycle is undoubtedly provoked by the inherent nature of shift work, which requires drivers to sleep at different times and for different periods (day/night cycle). This reinforces the need to submit drivers to PSG recordings and, when possible, to computed PSG evaluation when drivers are initially hired. This should be followed by annual check-ups that would identify possible shifts in the basal state and wake-sleep cycle along with sleeprelated complaints occurring during professional activities over a period of one year.

\section{Conclusion}

The present data demonstrate that Brazilian interstate bus drivers are highly dissatisfied with their sleep patterns, as revealed by the high rate of sleep complaints. These complaints are due to the life style/life habit of these individuals, associated with a totally irregular work shift that does not provide good physical or mental restoration during sleep.

The adequacy of the work shifts for the company, together with the physiological profile of the individual, i.e., the possibility for morning and evening shift workers to reconcile their work shift with their physiological pattern, plus good sleep hygiene, would greatly help to minimize the major complaints, with a consequent improvement in the quality of sleep and of life (7).

However, the above considerations suggest that it is difficult to establish the cause and the effect, i.e., to assess whether the factors that predispose to the sleep changes 
occur in a pre-morbid situation or are due to a work shift schedule that is not compatible with perfect sleep hygiene. Thus, the quality of life and of sleep of these drivers depends on a direct evaluation by computer PSG of the aspects discussed, so that these workers, as well as the population that uses this means of transportation, may ultimately benefit from this procedure.

Data referring to physical exercise revealed a significant shift in sleep-related complaint parameters, possibly indicating the advantages of physical exercise (19) and therefore raising the hypothesis that the complaints of the drivers about their work could be attenuated by this activity. This leads us to propose the possibility of minimizing sleep-related complaints as well as sleepiness through physical activity $(20,21)$. Fur- thermore, we recommend the exposure of drivers to 5000 lux each time they have an official coffee break at a stopover, which could help delay the increase of melatonin secretion since a 20-min exposure would delay the liberation of melatonin for $2 \mathrm{~h}(22)$. This is based on the use of bright light therapy in the delaying of melatonin secretion (23). We believe that this therapy could be instrumental in minimizing sleepiness-related complaints, since the maximum rate of melatonin secretion occurs in the final third of the night, which corresponds to the period during which the body undergoes a temperature drop. In this way, drivers would present sleepiness during periods close to the beginning of the morning cycle. This could also help inhibit the secretion of this hormone.

\section{References}

1. Hauri P (1992). The Sleep Disorders. Upjohn Company, Kalamazoo, MI.

2. Florez-Lozano JÁ (1980). Aspectos psicofisiológicos da fadiga. Revista Brasileira de Saúde Ocupacional, 29: 19-23.

3. Stampi C, Davis B \& Hasan J (1992). Correlation Between Physiological Measures of Alertness and Driver Fatigue Assessed by the TOPS Driving Simulator Test: a Pilot Study. Technical Report 2417-1, 3. Systems Tecnology, Inc., Hawthorne, CA.

4. Del Giglio SB (1988). Estudo da ocorrência de queixas de insônia, de sonolência excessiva diurna e das relativas às parassonias na população adulta da cidade de São Paulo. Doctoral thesis, Escola Paulista de Medicina, São Paulo.

5. Beck AT, Ward CH, Mendelson M, Mock JE \& Erlaugh J K (1961). An inventory for measuring depression. Archives of General Psychiatry, 4: 561-571.

6. Spielberger CD, Gorshusch RL \& Lushene E (1970). Manual for the State-Trait Anxiety Inventory ("Self-Evaluation Questionnaire"). Consulting Psychologist Press, Palo Alto, CA.

7. Akerstedt T (1995). Work hours, sleepiness and the underlying mechanisms. J ournal of Sleep Research, 4: 15-22.

8. Bussab WO \& Morettin PA (1997). Métodos Quantitativos: Estatística Básica. 4th edn. Atual Editora Ltda., São Paulo, 1-37.
9. ABIPEME (1978). Proposição para um novo critério de classificação sócioeconômica. Mimeo.

10. Palma BD, Andersen ML, Mello MT \& Tufik S (1997). Sleep complaints in São Paulo city: A comparison between the 1987 and 1995. In: Associated Professional Sleep Societies, 11th Annual Meeting San Francisco 1997, Abstract Book, San Francisco (Abstract 491).

11. Horne J A \& Ostberg O (1977). Individual differences in human circadian rhythms. Biological Psychology, 5: 179-190.

12. Hughes DG \& Folkard S (1976). Adaptation to an 8 hour shift in living routine by members of a socially isolated community. Nature, 264: 432-434.

13. Horne J A, Brass CG \& Pettit NA (1980). Circadian performance differences between "morning" and "evening types". Ergonomics, 23: 129-136.

14. Mitler MM, Dinges DF \& Dement WC (1994). Sleep medicine, public policy and public health. In: Kryeger MH, Roth T \& Dement WC (Editors), Principles and Practice of Sleep Medicine. 2nd edn. W.B. Saunders \& Co., Philadelphia, 453-462.

15. Yules RB, Lippsman ME \& Freedman DX (1997). Alcohol administration prior to sleep: the effect on EEG sleep stages. Archives of General Psychiatry, 19: 94-97.

16. Rundell $\mathrm{OH}$, Lester BK, Griffiths WS \&
Willians HL (1972). Alcohol and sleep in young adults. Psychopharmacologia, 26: 201-218.

17. Roehrs $T$, Zwyghuizen-Doorenbos A, Timms U, Zorick F \& Roth T (1989). Sleep extension, enhanced alertness and sedating effects of ethanol. Pharmacology, Biochemistry and Behavior, 34: 321-324.

18. McArdle WD, Kath FKI \& Kath VL (1992). Fisiologia do exercício, energia, nutrição e desempenho humano. 3rd edn. Guanabara Koogan, Rio de J aneiro.

19. Youngstedt SD, O'Connor PJ \& Dishman RK (1997). The effects of acute exercise on sleep: A quantitative synthesis. Sleep, 20: 203-214.

20. Cagnacci A (1992). Melatonin: a major regulator of the circadian rhythm of Coors temperature in humans. J ournal of Clinical Endocrinology, 75: 447-452.

21. Barrett J , Lack L \& Morris M (1993). The sleep-evoked decrease of body temperature. Sleep, 16: 93-99.

22. Kostoglou-Athanassiou I, Treacher DF, Wheeler MJ \& Forsling ML (1998). Bright light exposure and pituitary hormone secretion. Clinical Endocrinology, 48: 73-79.

23. Zawilska J B (1996). Melatonin as a chemical indicator of environmental light-dark cycle. Acta Neurobiologiae Experimentalis, 56: 757-767. 